\title{
Lässt sich das Karzinomrisiko aus Kolostrumzellen ablesen?
}

Im Kolostrum, der Erstmilch, die eine Mutter nach der Geburt ihres Kindes abgibt, finden sich auch Zellen aus dem Brustgewebe. Diese Zellen können möglicherweise dazu genutzt werden, Frauen mit einem erhöhten Brustkrebsrisiko zu erkennen.

- Wissenschaftler der University of Masssachusetts in Amherst sammelten Kolostrumproben von rund 250 Frauen, bei denen eine Biopsie bevorstand, und untersuchten sie auf epigenetische Signale. 38 solcher sogenannter Tumor hemmender Gene sind bekannt. Veränderungen in diesen Genen - erkennbar durch eine höhergradige Methylierung - würden auf ein erhöhtes Brustkrebsri- siko hindeuten. Die Analysen der Kolostrumzellen wurden mit den Biopsieergebnissen verglichen.

Bei 104 Frauen, bei denen mit der Biopsie der Krebsverdacht nicht bestätigt werden konnte, war auch die ZellDNA nicht verändert. Doch bei denjenigen, bei denen die Biopsie die Diagnose Brustkrebs bestätigte, war das typische RASSF1-Gen pathologisch verändert, also höher methyliert.

\section{Kommentar}

Wenn auch die Zahl der Untersuchungen klein ist, erlaubt sie nach Meinung der Autoren die Aussage, dass die Untersuchung der DNA der Epithelzellen im Kolostrum ein brauchbares Mittel zur Brustkarzinomvor- hersage ist und fortgesetzt werden sollte. Die Zahl der Untersuchungen muss erhöht werden. Langzeituntersuchungen müssen klären, ob die gefundene Assoziation auch langfristig ist. Da viele Frauen irgendwann im Leben ein Kind bekommen, könnte mit dieser Methode bei einem hohen Anteil der weiblichen Bevölkerung das Brustkrebsrisiko bestimmt werden. Die Untersuchung selbst ist nicht invasiv, nicht teuer und genau.

K. MALBERG $\equiv$

- K. Arcaro et al.

(University of Massachussetts, Veterinary and Animal Sciences, 300 Mass. Ave, Amherst, MA 01003, USA; E-mail: karcaro@nre.umass.edu). Breast milk may provide a personalized screen of breast cancer risk. American Association for Cancer Research 2011, April 4

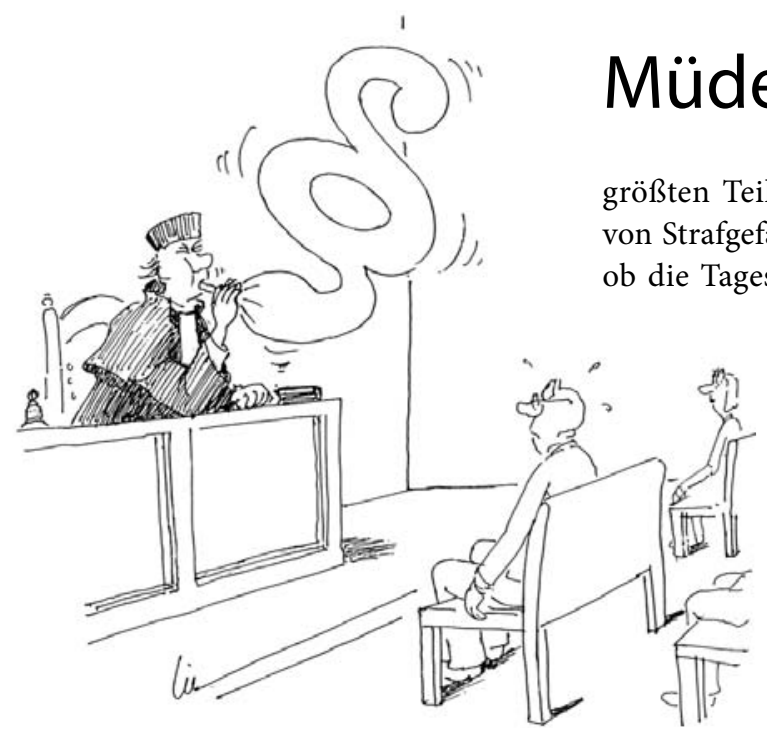

Nach der reinen Rechtslehre, sollten sich Gerichte nur an Fakten und Gesetzen orientieren. Doch die Experten meinen, dass Richtersprüche auch von psychologischen, politischen und sozialen Faktoren beeinflusst werden.

- Wissenschaftler der Ben Gurion University in Beer Sheva (Israel) analysierten 1112 Richterentscheidungen - zum den Antrag nahm von rund 65\% am Anfang kontinuierlich bis auf fast Null am Ende ab. Nach jeder Pause stieg die Zahl der positiven Richtersprüche wieder auf fast $65 \%$, um danach wieder abzufallen.

\section{Kommentar}

Aus früheren Untersuchungen ist bekannt, dass Menschen, wenn sie mental ermüden, dazu neigen, Entscheidungen zu vereinfachen. Im Fall der Richter überlegt man also nicht lange, ob ein Gefangener eine Freilassung zur Bewährung verdient hat, sondern lässt ihn weiter hinter Gittern schmoren. Es sind sich nicht nur Richter, deren Entscheidung von der Müdigkeit beeinflusst wird. Vielleicht machen auch wir Ärzte uns - müdigkeitsbedingt-gelegentlich die eine oder andere Entscheidung etwas zu einfach.

K. MALBERG

- S. Danzinger et al.

(Korrespondenz: J. Levav, Columbia Business School, Columbia University, New York, NY 10027, USA; E-mail: jl2351@columbia.edu) PNAS 2011 Published ahead of print April 11, 2011, doi:10.1073/pnas.1018033108 